\title{
Front Matter: Volume 11448
}

, "Front Matter: Volume 11448," Proc. SPIE 11448, Adaptive Optics Systems VII, 1144801 (21 January 2021); doi: 10.1117/12.2591718

SPIE. Event: SPIE Astronomical Telescopes + Instrumentation, 2020, Online Only 


\title{
Adaptive Optics Systems VII
}

\author{
Laura Schreiber \\ Dirk Schmidt \\ Eise Vemet \\ Editors
}

\section{4-22 December 2020}

Online Only, United States

Sponsored and Published by

SPIE

Volume 11448

Part One of Two Parts 
The papers in this volume were part of the technical conference cited on the cover and title page. Papers were selected and subject to review by the editors and conference program committee. Some conference presentations may not be available for publication. Additional papers and presentation recordings may be available online in the SPIE Digital Library at SPIEDigitalLibrary.org.

The papers reflect the work and thoughts of the authors and are published herein as submitted. The publisher is not responsible for the validity of the information or for any outcomes resulting from reliance thereon.

Please use the following format to cite material from these proceedings:

Author(s), "Title of Paper," in Adaptive Optics Systems VII, edited by Laura Schreiber, Dirk Schmidt, Elise Vernet, Proceedings of SPIE Vol. 11448 (SPIE, Bellingham, WA, 2020) Seven-digit Article CID Number.

ISSN: 0277-786X

ISSN: 1996-756X (electronic)

ISBN: 9781510636835

ISBN: 9781510636842 (electronic)

Published by

SPIE

P.O. Box 10, Bellingham, Washington 98227-0010 USA

Telephone +1 3606763290 (Pacific Time) · Fax +1 3606471445

SPIE.org

Copyright (c) 2020, Society of Photo-Optical Instrumentation Engineers.

Copying of material in this book for internal or personal use, or for the internal or personal use of specific clients, beyond the fair use provisions granted by the U.S. Copyright Law is authorized by SPIE subject to payment of copying fees. The Transactional Reporting Service base fee for this volume is $\$ 21.00$ per article (or portion thereof), which should be paid directly to the Copyright Clearance Center (CCC), 222 Rosewood Drive, Danvers, MA 01923. Payment may also be made electronically through CCC Online at copyright.com. Other copying for republication, resale, advertising or promotion, or any form of systematic or multiple reproduction of any material in this book is prohibited except with permission in writing from the publisher. The CCC fee code is $0277-$ $786 \times / 20 / \$ 21.00$.

Printed in the United States of America by Curran Associates, Inc., under license from SPIE.

Publication of record for individual papers is online in the SPIE Digital Library.

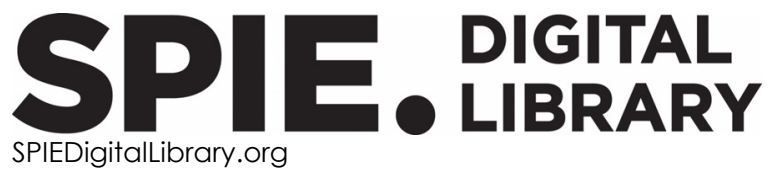

Paper Numbering: Proceedings of SPIE follow an e-First publication model. A unique citation identifier (CID) number is assigned to each article at the time of publication. Utilization of CIDs allows articles to be fully citable as soon as they are published online, and connects the same identifier to all online and print versions of the publication. SPIE uses a seven-digit CID article numbering system structured as follows:

- The first five digits correspond to the SPIE volume number.

- The last two digits indicate publication order within the volume using a Base 36 numbering system employing both numerals and letters. These two-number sets start with $00,01,02,03,04$, 05, 06, 07, 08, 09, OA, OB ... 0Z, followed by 10-1Z, 20-2Z, etc. The CID Number appears on each page of the manuscript. 


\section{Contents}

\section{Part One}

\section{ASTRONOMY WTH AO}

1144808 Planet fomation with all flavors of adaptive optics: VLT/ MUSE's lasertomography adaptive optics to directly image young accreting exoplanets [11448-3]

1144809 Constraining orbits and masses of stellar companions with SCEXAO imaging and REACH spectroscopy [11448-4]

PROCESSING TECHNIQUES FOR AO CORRECTED DATA I

11448 OA Review of PSF reconstruction methods and application to post-processing (Invited Paper) [11448-5]

UPG RADES AND NEW AO INSTRUMENTS IN DEVEOPMENT

11448 OD MAVIS: the adaptive optics module feasibility study [11448-9]

11448 OE Keck all sky precision adaptive optics [11448-11]

PROCESSING TECHNIQUES FOR AO CORREC TED DATA II

11448 OG Precise photometry and astromety in the core of the globular cluster NGC 6121 using PSF-R tec hniques [11448-13]

$11448 \mathrm{OH} \quad$ Starfinder2: a software package for identification and analysis of point-like sources in adaptive optics images with spatially variable PSF [11448-15]

\section{STATUS OFAO PROJ ECTS I}

11448 OK Ovenview of AO activities at Subaru Telescope (Invited Paper) [11448-19]

11448 ON Status of the SC EXAO instrument recent technology upgrades and path to a system-level demonstrator for PSI [11448-22] 
MODEUNG OF AO SYSTEMS

1144800 Challenges in simulating advanced control methods for AO [11448-334]

11448 OP Overcoming the effect of pupil distortion in multic onjugate adaptive optics [11448-23]

NEW AO SYSTEMS ON SKY

11448 OT First light with adaptive optics: the perfomance of the DKISThigh-order adaptive optics (Invited Paper) [11448-27]

11448 OU Prediction of the planet yield of the MaxProtoPlanetS high-contrast survey for H-alpha protoplanets with MagAO-X based on first light contrasts [11448-28]

11448 OV MUSE+GALACS: the first years [11448-29]

11448 OW Design and performance of the PALM-3000 $3.5 \mathrm{kHz}$ upgrade [11448-31]

AO INSTRUMENIS ON EITS

11448 OY MAORY: the adaptive optics module for the Extremely Large Telesc ope (ELT) [11448-33]

WAVERONTSENSING FOR ELTS

1144812 Petalometry for the ET: dealing with the wavefront discontinuities induced by the telescope spider[11448-39]

REAL-TIME CONTROUERS FOR ELTS

1144814 Real-time control (RIC) systems and hardware considerations for next generation adaptive optics (AO) RIC (Invited Paper) [11448-41]

1144815 Hard real-time core software of the AO RIC COSMIC platform: architecture and perfomance [11448-172]

\section{WAVERONTSENSING}

1144819 First on-sky results of the CAWS wavefront sensor on the CANARY expeniment [11448-48]

iv 
11448 1B Oveniew on wavefront comector technologies for astronomy and solar adaptive optics systems (Invited Paper) [11448-49]

11448 1D TMTdeformable mimor prototype testing and verification [11448-51]

11448 IE A new adaptive secondary minor for astronomy on the University of Hawaii 2.2-meter telescope [11448-52]

MACHINE LEARNING IN AO

11448 1G Deep leaming-based focal plane wavefront sensing for classical and coronagraphic imaging [11448-56]

$11448 \mathrm{1H} \quad$ Convolutional neural networks for object-agnostic wavefront sensing in the presence of noise [11448-325]

TURBULENCE CHARAC TERIZATION AND FORECASTING

11448 1] Turbulence nowcast for the Ceno Paranal and Cemo Amazones obsenatory sites [11448-59]

$114481 \mathrm{~K} \quad$ Comparison of atmosphere profilers at Paranal and atmosphere parameters statistics: AOF-profiler, STEREO-SCIDAR, MASS-DIMM, LGS-WFS [11448-60]

PROGRESS OF UPCOMING SYSTEMS

$114481 \mathrm{~L}$ Development and status of MAPS, the MMTAO exoPlanet characterization system [11448-61]

$114481 \mathrm{M}$ SHARK-NIR, toward the installation at the Large Binocular Telescope [11448-62]

1144810 ULTIMATE-START: Subaru tomography adaptive optics research experiment project oveniew [11448-64]

11448 1P TROIA adaptive optics system for DAG Telescope [11448-65]

NEW IDEAS

$114481 \mathrm{Q}$ The use of random phase pattems composed of huge number of elements for wavefront reconstruction in adaptive optics [11448-66] 
$114481 T \quad$ Using the generalised-optical differentiation wavefront sensor for laser guide star wavefront sensing [11448-69]

\section{LASER GUIDE STARS ॥}

$114481 \mathrm{U}$ Australia's first laser guide star: design and telescope integration at Mount Stromlo Obsenatory [11448-73]

11448 IV The use of sodium layer density anisotropies to fully measure the atmospheric turbulence, including tip-tilt, foc us, and higherorder abenations [11448-74]

TURBULENCE CHARAC TERIZATION

11448 1W Comection of finite spatial and temporal sampling effects in stereo-SCIDAR [11448-75]

PATHFNDERS

$114481 Z$ Validating advanced wavefiont control techniques on the SCEXAO testbed/instrument [11448-78]

POSTER SESSION: CONIROLAND CALBRATION

1144829 An advanced SCAO control concept based on mechanical mimor modes for MEIIS [11448-88]

$114482 \mathrm{~A} \quad$ Identification and model predic tive control of an expenimental adaptive optics setup utilizing Kautz basis functions [11448-90]

11448 2C Predic tive leam and apply: MAVIS application - leam [11448-93]

11448 2E ALOU: presentation and first steps [11448-95]

$114482 \mathrm{H} \quad$ GPI 2.0: optimizing reconstructor performance in simulations and preliminary contrast estimates [11448-100]

POSTER SESSION: REALTIME CONTROUERS

11448 2K A feasibility study of the open source DARC RIC software as a baseline for a generic Gemini AO RIC [11448-142]

11448 2L Predictive leam and apply: MAVIS application - apply [11448-143]

vi 
11448 2M MAVIS real-time control system: a high-end implementation of the COSMIC platform [11448-144]

$114482 \mathrm{~N}$ Adaptive optics real-time control with the compute and control for adaptive optics (Cacao) software framework [11448-145]

1144820 Implementation and initial test results of the new Keck real time controller [11448-146]

POSTER SESSION: AO MODEING, ANALYSIS, AND SIMULATION

$1144825 \quad$ MAORY AO performances[11448-162]

$114482 \mathrm{~V}$ Design of a perfomance venification unit for the MAORY system [11448-166]

POSTER SESSON: ASTRONOMY WTH AO

11448 2W MAORY science preparation status [11448-167]

POSTER SESSON: EIS PROJ ECTSTATUSES

$114482 X \quad$ The Giant Magellan Telesc ope high contrast phasing testbed [11448-149]

$114482 Y \quad$ InfraRed Imaging Spectrograph (IRIS) on TMT: OIWFS opto-mechanical design update [11448-150]

1144830 MAORY calibration unit design status [11448-153]

1144832 MAORY main structure design: general oveniew [11448-156]

1144834 MAORY: optical configuration and expected optical perfomances [11448-158]

1144835 Optomechanical design of MAORY post focal relay optics [11448-159]

POSTER SESSION: PROCESSING OF AO CORRECTED DATA

1144837 MICADO PSF-reconstruction work package description [11448-169] 
POSTER SESSION: REALTIME CONTROUERS

1144839 MAORY RIC, a status update [11448-173]

POSTER SESSION: WAVERONTSENSING

$114483 \mathrm{l} \quad$ Evaluating the perfomance of an Ingot wavefront sensor for the ETT good news from simulations [11448-194]

11448 3N Design study for a three-sided reflective pyramid wavefront sensor for Shane AO [11448-200]

\section{Part Two}

POSTER SESSION: AO MODEUNG, ANALYSIS, AND SIMULATION

11448 3R MAVIS: System modelling and perfomance prediction [11448-103]

$114483 S$ The adaptive optics simulation analysis tool(kit) (AOSAT) [11448-104]

11448 3T A versatile turbulence simulator for high-resolution imaging studies of astronomical targets [11448-105]

11448 3V Operational forecast of the PSF figures of menit [11448-341]

11448 3W New concepts in vector-apodizing phase plate coronagraphy [11448-109]

$114483 Z$ Analytical model-based analysis of long-exposure images from ground-based telescopes [11448-111]

1144842 On the sequence of deformable minors in MCAO: findings from an on-sky, closed-loop experiment [11448-114]

\section{POSIER SESSION: MACHINE LEARNING IN AO}

1144849 Self-optimizing adaptive optics control with reinforcement leaming [11448-205]

11448 4A Non-parametric point spread function modelling for adaptive optics systems [11448-206]

11448 4C Wavefront prediction using artificial neural networks with CANARY telemetry [11448-209]

11448 4E Statistical leaming as a new approach for optical turbulence forecasting [11448-213] 
11448 4F Neural network wavefiont sensor for the Large Binoc ularTelescope Observatory [11448-214]

11448 4G Improved training for the deep leaming wavefiont sensor [11448-215]

$114484 \mathrm{H} \quad$ Wide-field wavefiont sensing with convolutional neural networks and ordinary least squares [11448-324]

11448 4] Denoising wavefront sensor images with deep neural networks [11448-327]

POSTER SESSION: NEW AO SYSTEMSON SKY

11448 4L MagAO-X first light [11448-218]

11448 4M Multi-core fibre-fed integral-field unit (MCIFU): oveniew and first-light [11448-219]

POSTER SESSION: PROGRESS OF UPCOMING SYSTEMS

11448 4R Optical design of the adaptive optics system for DAG, the new 4 m Turkish telescope [11448-293]

$114484 \mathrm{U}$ Calibrating ERIS data: as-built capabilities and performances of the instrument's inner calibration unit [11448-296]

POSTER SESSION: ASTRONOMY WTH AO

11448 4V Finding exoplanets in the habitable zone with light echoes [11448-118]

POSTER SESSION: PROCESSING OF AO CORRECTED DATA

$114484 Z$ The power spectrum extended technique applied to images of binary stars in the infrared [11448-123]

$1144850 \quad$ Post-AO image reconstruction with the PSE algorithm [11448-124]

$1144853 \quad$ High resolution residual wavefront reconstruction for c losed-loop adaptive optics systems [11448-129]

$1144854 \quad$ Incomorating adaptive optics controls history in post-processing of ground-based coronagraph models [11448-132]

1144856 Real-time PSF estimation with GIRMOS[11448-135] 
1144859 Analyzing long-term performance of the Keck-II adaptive optics system [11448-138]

11448 5A Exoplanet imaging data challenge: benchmarking the various image processing methods for exoplanet detection [11448-321]

POSTER SESSION: STATUS OF C URRENTAO PROJ EC TS

11448 5E Multi-cascade image comection system for the Large Solar Vacuum Telescope [11448-178]

$114485 \mathrm{H}$ The ORP on-sky community access program for adaptive optics instrumentation development [11448-181]

$114485 \mathrm{I} \quad$ Enhanced seeing mode: a technique for improving wide-field angular resolution in the near-infrared using adaptive optics [11448-182]

11448 5] Design and development of a high-speed visible pyramid wavefront sensor for the MMTAO system [11448-332]

\section{POSTER SESSSON: WAVERONTCORRECTORS}

11448 5K GMTadaptive secondary minors subsystem final design [11448-183]

$114485 \mathrm{~L} \quad$ Laboratory testing and calibration of the upgraded MMTadaptive secondary mimor [11448-331]

$114485 \mathrm{~N}$ Research on the large adaptive deformable mimor base on giant magnetostric tive material actuators [11448-224]

1144850 Adaptive secondary mimors performance and reliability improvements at the Large Binocular Telescope [11448-225]

$114485 \mathrm{Q}$ High precision shape control of large deformable minors for adaptive optics [11448-227]

11448 5R Performance analysis of the adaptive secondary minor for the UH2.2 telesc ope [11448-229]

$114485 S \quad$ Photo-controlled deformable mimor based on silic on photoconductor [11448-230]

11448 5T Adaptive secondary mimors upgrades at the Large Binocular Telescope [11448-232]

11448 5U Developing adaptive secondary mimor concepts forthe APF and W.M. Keck Observatory based on HVR technology [11448-233]

$114485 \mathrm{~V}$ Performance of large-format deformable mimors constructed with TNO variable reluctance actuators [11448-234] 
1144860 Aligning and testing the ingot wavefront sensor in the lab [11448-241]

1144861 Test bench demonstration of the geometric wavefront sensor [11448-242]

1144862 Wind estimates from layer-oriented MCAO telemetry: working towards wavefront predic tion [11448-243]

1144865 Measurements of image quality and surface shape of mic rolens anays for Shack-Hartmann wavefront sensors [11448-247]

1144868 Ingot wavefront sensor: from the Founier End2End numerical simulation to the LOOPS test bench [11448-250]

11448 6D Focal plane wavefront sensing on SUBARU/SCEXAO [11448-255]

11448 6G Injecting pupil binary intensity map into the laboratory adaptive optics bench using phase-only LCoS-SUM device [11448-258]

$114486 \mathrm{H} \quad$ Fast pixel difference algorithm for determining piston step between optical mimor segments [11448-259]

11448 6] GPI 2.0: design of the pyramid wave front sensor upgrade for GPI [11448-262]

\section{POSTER SESSION: LASER GUIDE STAR SYSTEMS}

1144865 Alignment and tolerancing of a mimor relay system for a newly upgraded LGS system on Subaru Telescope [11448-273]

\section{POSTER SESSION: PATHFNDERS, NEW PROPOSED SYSTEMS, AND CONCEPIS}

11448 6W MAVIS adaptive optics module optical design [11448-280]

$114486 \mathrm{Y}$ Optical design and preliminary results of NEWEARTH, first Canadian high-contrast imaging laboratory test bench [11448-282]

$114486 Z$ Development of an expenimental optical adaptive optics for small telesc opes [11448-283]

1144871 Dimensioning adaptive optics for future VLT projects [11448-286]

1144872 The multi-object adaptive optics system for the Gemini infra-red multi-object spectrograph [11448-287] 
1144873 Upgrading the Gemini Planet Imagercalibration unit with a photon counting focal plane wavefiont sensor [11448-288]

1144874 Ground-based adaptive optics observations with orbiting nanosatellite (GO-ON) [11448-290]

1144875 RISTRETIO: a pathfinder instrument for exoplanet atmosphere characterization [11448-329]

\section{POSTER SESSION: STATUS OF CURRENTAO PROJ ECTS}

1144876 Developing the prototype adaptive optics system for the Gemini infra-red multi-object spectrograph [11448-297]

1144877 Development of multi-conjugate adaptive optics system for monitoring of solar system planets [11448-298]

1144878 Extremely high-contrast, high spectral resolution spectrometer REACH for the Subaru Telesc ope [11448-299]

$114487 C \quad$ New NIR spectro-polarimetric modes for the SCEXAO instrument [11448-304]

11448 7D Wavefront correction using MEMS deformable mimor for Earth obsenvation satellite with large segmented telesc ope [11448-305]

$114487 \mathrm{~F} \quad$ Potential optical design of a multi-conjugate adaptive optics instrument based on a modified Offner concentric relay for Gemini North [11448-322]

$114487 \mathrm{G}$ KalAO the swift adaptive optics imager on the 1.2m Euler Swiss telesc ope in La Silla, Chile [11448-328]

$114487 \mathrm{H} \quad$ On-sky performance and recent results from the Subaru coronagraphic extreme adaptive optics system [11448-330]

\section{POSTER SESSION: TURBULENCE CHARAC TERIZATION, MEASUREMENT, AND MODEUNG}

$114487 \mathrm{~K}$ Turbulence monitoring at Calem obsenvatory with the generalized differential image motion monitor [11448-310]

$114487 \mathrm{~L}$ The effect of intermittency of the jitter of astronomic images in the high-altitude observations [11448-311]

1144870 Which isoplanatic patch size for high angular resolution techniques? [11448-314]

$114487 \mathrm{P}$ Atmospheric turbulence profiling with a Shack-Hartmann wavefront sensor[11448-315]

11448 7Q Toward an optimal prediction of atmospheric turbulence by means of WRF model [11448-316] 
$11448 \pi \quad$ A program to monitorand improve routine AO operations [11448-320]

$114487 \mathrm{U}$ Gaussian phase autocomelation as an accurate compensator for Fr-based atmospheric phase screen simulations [11448-323] 
Proc. of SPIE Vol. 11448 1144801-14

Downloaded From: https://www.spiedigitallibrary.org/conference-proceedings-of-spie on 26 Apr 2023 Terms of Use: https://www.spiedigitallibrary.org/terms-of-use 